\title{
In vitro proteolysis of myofibrillar and sarcoplasmic proteins of white muscle of sea bass (Dicentrarchus labrax L.):
}

\section{effects of cathepsins $B, D$ and $L$}

\author{
C. Ladrat*, V. Verrez-Bagnis, J. Noël and J. Fleurence \\ IFREMER, DRV-VP-BPQ, BP21105, 44311, Nantes Cedex 3, France \\ *: Corresponding author : Tel.: +33-240374000; fax: +33-240374071; email:cladrat@ifremer.fr
}

\begin{abstract}
:
The purpose of this study was to obtain additional information regarding proteolysis mechanisms and disorganization of fish myofibrils resulting in a loss of flesh quality. The ability of cathepsins to degrade in vitro myofibrillar and sarcoplasmic proteins from fish muscle was investigated in order to explain their role in post mortem softening. This led to the identification of substrates of the enzymes.

Cathepsins degraded myosin heavy chain and $\alpha$-actinin. Tropomyosin and actin were only susceptible to the action of cathepsin L. Troponin T (assumed $32 \mathrm{kDa}$ component) was resistant only to the action of cathepsin D. Desmin was degraded by cathepsins B and L. Slight changes of some other myofibrillar or cytosolic proteins were also observed (creatine kinase and other unidentified proteins). When compared with protein modifications observed in stored post mortem muscle, these results suggest that cathepsin $\mathrm{D}$ (if location is in the cytosol and if $\mathrm{pH}$ conditions for activity are met in post mortem muscle) could be involved in a post mortem myofibrillar degradation mechanism.
\end{abstract}

Keywords: In vitro proteolysis; Cathepsins; Fish muscle proteins; Post mortem degradation 


\section{Introduction}

Postmortem tenderization is one of the most unfavourable quality changes in fish muscle in contrast with those of mammalian meats. Therefore, the biochemical processes have been extensively studied in order to identify potential quality indicators or to determine means to control postmortem degradation. Muscle tissue postmortem evolution is characterized by successive biochemical reactions and autolytic modifications resulting in disorganisation of the muscular structure. A proteolytic degradation of myofibrillar and connective tissue components is observed in this tissue. But an understanding of the mechanisms involved in these changes especially in fish muscle has not reached general agreement.

There has been considerable debate about the specific protease responsible for postmortem changes. The participation of various proteinases in autolytic processes of ice-stored fish depends on the following : location of the enzymes in cytosol and/or factors affecting tissue compartmentization, presence of activators or inhibitors and the susceptibility of the proteins responsible for muscle integrity to in situ cleavage by the respective enzymes. Two major intracellular degradative pathways have been involved in these degradations : a lysosomal way including cathepsic proteases and a cytosolic calcium-dependent way with calpains. Other proteases such as metalloproteinases, may also have a role in postmortem fish muscle changes especially on extracellular matrix components such as collagen (Kubota, Kinoshita, Kubota, Yamashita, Toyohara \& Sakaguchi, 2001). Purified proteasome from lobster (Mykles \& Haire, 1995) and rabbit (Matsuishi \& Okitani, 1997) hydrolysed myofibrillar proteins although it required activation by heat or addition of SDS. Thus, its role in postmortem degradation could be of lesser importance even if it also needs to be further clarified. The respective contribution of these systems to myofibrillar protein degradation is still unclear. But it is highly likely that several protease groups could synergistically contribute to postmortem tenderization. In particular, calpains are believed to initiate the disintegration of Z line by a titin cleavage (Astier, Labbe, Roustan \& Benyamin, 1991) which weakens the titin/ $\alpha$-actinin interaction and results in the release of intact $\alpha$-actinin from $Z$ lines (Papa, Alvarez, Verrez-Bagnis, Fleurence \& Benyamin, 1996) before its further proteolysis by proteasome and various cathepsins (Goll, Thompson, Taylor \& Christiansen, 1992; Lamare, Taylor, Farout, Briand \& Briand, 2002) especially in mammalian muscles.

Postmortem changes in sea bass muscle include the weakening and the disorganisation of the $\mathrm{Z}$ line structure, the detachment of sarcolemma, and the degradation of dystrophin (Papa et al., 1997) as well as the degradation of titin and nebulin (Astier et al., 1991) and the release and proteolysis of $\alpha$-actinin from the $\mathrm{Z}$ line (Papa et al., 1996). We found that desmin remained unchanged after a 4 day ice storage in cultured sea bass muscle but was highly degraded in wild fish such as sardine (Verrez-Bagnis, Noël, Sautereau \& Fleurence, 1999). A $16 \mathrm{kDa}$ sarcoplasmic protein was also shown to undergo proteolysis upon storage (VerrezBagnis, Ladrat, Morzel, Noël \& Fleurence, 2001).

Moreover, three different calpain-like activities have been detected in postmortem white muscle from sea bass. They have similar biochemical properties with those of terrestrial vertebrates but are expressed differently throughout the year (Ladrat, Chaplet, Verrez-Bagnis, Noël \& Fleurence, 2000). In a previous report, we found that m-calpain was able to release myofibrillar components in soluble fraction : tropomyosin, $\alpha$-actinin and some other nonidentified proteins ; it degraded myosin heavy chain, $\alpha$-actinin and desmin but it left actin and tropomyosin intact. A $26.5 \mathrm{kDa}$ sarcoplasmic component was also degraded by calpain (Verrez-Bagnis, Ladrat, Noël \& Fleurence, 2002).

Until now, the effect of cathepsins on sea bass muscle proteins has not been investigated. Lysosomes are known to harbour about 13 cathepsins (Kolodziejska \& Sikorski, 1995). Among them, cathepsins B, D, L, L-like have been purified from fish muscle. Cathepsins B, 
$\mathrm{D}$ and $\mathrm{L}$ are considered to be critical in fish muscle postmortem modifications (Aoki \& Ueno, 1997; Jiang, Lee \& Chen, 1996; Jiang, Wang \& Chen, 1992; Ogata, Aranishi, Hara, Osatomi \& Ishihara, 1998; Yamashita \& Konagaya, 1990a) or in gel softening during setting of mackerel surimi (Ho, Chen \& Jiang, 2000; Yamashita \& Konagaya, 1991). Cathepsins A and C contribute to the hydrolysis of muscle protein in a concerted action with the other cathepsins (Kolodziejska \& Sikorski, 1995).

In this paper, we investigated the effects of cathepsins on myofibrillar and sarcoplasmic components to analyse in more detail their role in postmortem degradation of fish muscle. Based upon literature, we will focus on the lysosomal enzymes cathepsins B, D and L.

\section{Material and methods}

Fish

Sea bass (Dicentrarchus labrax L.) was purchased alive from a local sea farm in Vendée (France) and killed by decapitation in the laboratory. Dorsal white muscle samples were frozen in dry ice and kept at $-80^{\circ} \mathrm{C}$ until used for the preparation of sarcoplasmic proteins just before enzymatic digestion.

Protein preparations

Sarcoplasmic proteins were extracted from muscle frozen at death, by homogenisation in 4 volumes (w/v) of water containing $1 \mathrm{mM}$ EDTA. Solutions were centrifuged twice at 10000 g, $4^{\circ} \mathrm{C}$ for 15 minutes. Protein content was determined by Bradford assay (Bradford, 1976) using Bio-Rad reagent (Bio-Rad, Ivry-sur-Seine, France). Myofibrils preparation was performed on fresh sea bass muscle according to the method of Wang (Wang, 1982), suspended in $50 \%(\mathrm{v} / \mathrm{v})$ glycerol and stored at $-20^{\circ} \mathrm{C}$ until use. Protein content was estimated at $12.5 \mathrm{mg} / \mathrm{ml}$ by Bradford assay. Before incubation with proteolytic enzymes, one aliquot of this preparation $(800 \mu \mathrm{l})$ was taken, centrifuged thrice at $4000 \mathrm{rpm}$ for 15 minutes at ambient temperature with pellet being resuspended each time in $1000 \mu \mathrm{l}$ water. The final pellet was used directly for the reaction mixture.

\section{Protease preparations}

Since no cathepsin from fish is commercially available, we chose cathepsins from other organisms making the assumption that they exhibit a similar action toward proteins with respect to the cleavage specificity (Yamashita \& Konagaya, 1990b; Yamashita \& Konagaya, 1990c). Paramecium tetraucelia Cathepsin L was purchased from CALBIOCHEM (Merck Eurolab, Fontenay-sous-bois, France). Cathepsin B (C6286) and cathepsin D (C3138) both from bovine spleen were from SIGMA (Saint-Quentin-Fallavier, France).

Proteolytic digestions

The digestion mixture with cathepsins contained $5 \mathrm{mg} / \mathrm{ml}$ sarcoplasmic or myofibrillar proteins, $2 \mathrm{mM}$ EDTA, $0.1 \mathrm{M} \mathrm{KCl}$, enzymes and other additives as required in $50 \mathrm{mM}$ acetate buffer $\mathrm{pH}$ 5.5. $7 \mu \mathrm{g}$ cathepsin $\mathrm{B}$ was used for $1 \mathrm{ml}$ of digestion mixture in the presence of 5 $\mathrm{mM}$ DTT at $25^{\circ} \mathrm{C}$. $23 \mu \mathrm{g}$ cathepsin D per milliliter of incubation solution was used at $25^{\circ} \mathrm{C}$. 3 $\mu \mathrm{g} / \mathrm{ml}$ cathepsin L was used at $25^{\circ} \mathrm{C}$ in the presence of $5 \mathrm{mM}$ DTT. Incubations lasted up to 22 hours with aliquots sampled at 0-30 min- 1 hour- 2 hours- 4 hours-6 and 22 hours.

Controls were carried out without enzymes. Each digestion was done and analysed twice.

Two aliquots from the sarcoplasmic protein digestions were removed at specific intervals. Digestion in the first aliquot was stopped by rapid addition of $4 \mathrm{x}$ concentrated SDScontaining tracking dye and immediate heating for $3 \mathrm{~min}$ at $100^{\circ} \mathrm{C}$ while one volume of $5 \%$ TCA was added in the second aliquot. For myofibrillar proteins breakdown, a first aliquot was added to one volume of 5\% TCA ; the second aliquot was firstly centrifuged at $4000 \mathrm{rpm}$, at room temperature for $15 \mathrm{~min}$ in the presence of inhibitors to stop the reaction $(0.01 \mathrm{mM}$ E64, $0.01 \mathrm{mM}$ pepstatin A). Supernatant containing proteins released from myofibrils was added to $4 \mathrm{x}$ concentrated SDS-containing tracking dye. Pellet was solubilized in the same 
volume as initial aliquot of $40 \mathrm{mM}$ Tris buffer containing $8 \mathrm{M}$ urea ; 4x SDS-containing tracking dye was added before boiling for $3 \mathrm{~min}$.

TCA samples were treated as previously described (Verrez-Bagnis et al., 2002) to determine the amount of soluble peptides produced whose increase during digestion was evidence of effective activity of enzymes in the conditions used. Samples with SDS and dye were frozen until submission to SDS-PAGE.

SDS-PAGE and Western blots

SDS-PAGE and Coomassie Blue staining were performed in order to gain a general insight into modified proteins and blotting with immunodetection of specific proteins was performed. Tropomyosin, $\alpha$-actinin and desmin were followed by this method because of their key role in myofibrillar integrity ; they have also been described to undergo changes during postmortem storage in sea bass.

SDS-PAGE was carried out in a Mini-protean dual slab cell (Bio-Rad) according to the method of Laemmli (Laemmli, 1970) using 4-20\% polyacrylamide gradient gels. $5 \mu \mathrm{l}$ of sample from the digestion of sarcoplasmic proteins, $5 \mu \mathrm{l}$ of sample prepared from the pellet of digested myofibrillar proteins and $10 \mu \mathrm{l}$ from the corresponding supernatant were loaded into separated wells. Several sets of molecular weight markers have been used : a mixture of SDS$6 \mathrm{H}$ and SDS-7 from SIGMA for Coomassie blue stained gels and prestained markers from Bio-Rad for immunoblots as well as for some blue gels (Broad Range and Broad Precision prestained markers). Average molecular weights were estimated from several analysed gels. After migration, gels were subsequently stained with Coomassie Brilliant Blue R250 or blotted overnight at $15^{\circ} \mathrm{C}$ onto a $0.45 \mu \mathrm{m}$ nitrocellulose membrane at $30 \mathrm{~V}$ using a MiniTransblot Cell (Bio-Rad). Transfer buffer was as follows : $150 \mathrm{mM}$ glycine, $20 \mathrm{mM}$ Tris, 20 \% methanol, $0.01 \%$ SDS. Membranes were saturated with $8 \%$ skimmed milk reconstituted in $0.9 \% \mathrm{NaCl}$, incubated with rabbit antibodies diluted in $0.9 \% \mathrm{NaCl}$ for 2 hours at room temperature. They were then washed with phosphate buffered saline $(137 \mathrm{mM} \mathrm{NaCl}, 2.7 \mathrm{mM}$ $\mathrm{KCl}$ in $10 \mathrm{mM}$ phosphate buffer $\mathrm{pH}$ 7.4) containing $0.05 \% \mathrm{v} / \mathrm{v}$ Tween 20 and subsequently incubated with secondary goat anti-rabbit IgG alcaline phosphatase conjugate diluted with 0.9 $\% \mathrm{NaCl}$ containing $5 \%$ bovine serum albumin. Enzymatic detection was carried out using nitroblue tetrazolium / 5-bromo-4-chloro-3-indolyl phosphate (NBT/BCIP) as the substrate resulting in brown red bands. Primary antibodies included polyclonal anti- $\alpha$-actinin produced in the laboratory (1/300 dilution) and used on sarcoplasmic and myofibrillar proteins digestions, polyclonal anti-desmin (D8281, SIGMA, 1/200 dilution) and polyclonal antitropomyosin (T3651, SIGMA, 1/200 dilution). The two latter antidodies were used on myofibrillar proteins for in vitro proteolysis only.

Image analysis

The Coomassie Blue stained gels as well as the immunoblots were photographed with a CCD camera system (Image Master VDS-CL, Amersham Biosciences, Orsay, France) and analysed with 1D-Elite program (Amersham Biosciences).

\section{Results}

The present study made an inventory of the qualitative changes affecting muscular proteins from sea bass when digested by cathepsins in order to assess their ability to reproduce in vitro the postmortem changes observed in muscle.

Sarcoplasmic proteins

Sarcoplasmic proteins are mainly composed of enzymes associated with energy-producing metabolism (glycolysis, citrate cycle...) (Nakagawa, Watabe \& Hashimoto, 1988b). Except for parvalbumins (Gerday, 1982), they have been characterized only partially. Sarcoplasmic extracts resulted in 13 major protein bands (Figure 1A) and are comparable to the samples 
described by Nakagawa (Nakagawa, Watabe \& Hashimoto, 1988a). The most abundant protein bands are as follows in average molecular weights : $97 \mathrm{kDa}$, a doublet band at $60 \mathrm{kDa}$, $51 \mathrm{kDa}$, a 41 - $39 \mathrm{kDa}$ huge band, which is most probably a doublet band (these two bands are assumed to be respectively creatine kinase and aldolase by comparison with the patterns described by Nakagawa et al. (1988a)), and a $36 \mathrm{kDa}$ component assumed to be glyceraldehyde-3-phosphate dehydrogenase ; supplementary bands were observed at $34 \mathrm{kDa}$, $27 \mathrm{kDa}, 25 \mathrm{kDa}, 21.5 \mathrm{kDa}$, and $17 \mathrm{kDa}$. The last one was shown to disappear upon cold storage (Verrez-Bagnis et al., 2001) and was further identified as a nucleoside diphosphate kinase by N-terminal sequencing (data not shown). Finally two protein bands at about 13 and 12 kDa could be parvalbumins (Focant, Mélot, Collin, Chikou, Vandewalle \& Huriaux, 1999; Girija \& Rehbein, 1988).

Electrophoretic separation of hydrolysis products by cathepsin B (Figure 2A) revealed that the most susceptible protein to degradation was the huge band around $40 \mathrm{kDa}$ which is then visibly dissociated into two bands. The $41 \mathrm{kDa}$ creatine kinase is likely degraded by cathepsin B. Two fragments (30.5 kDa and $20.5 \mathrm{kDa}$ ) were generated at the end of the incubation with cathepsin B. The other protein bands remained unchanged. Cathepsin D (Figure 2B) was not able to degrade any sarcoplasmic proteins as shown on the Coomassie blue stained gel whereas cathepsin L (Figure 2C), like cathepsin B, was able to dissociate the 41-39 doublet probably by degrading both bands. The $21.5 \mathrm{kDa}$ component is also susceptible to proteolysis by cathepsin $\mathrm{L}$ and two fragments ( 24 and $20.5 \mathrm{kDa}$ ) appeared upon incubation with cathepsin L.

We were able to detect some $\alpha$-actinin by the immunological method in the sarcoplasmic fraction. It was not degraded by cathepsin B, or cathepsin D or cathepsin L (data not shown). Myofibrillar proteins

After electrophoresis and Coomassie blue staining of the myofibrillar proteins, 14 bands were observed. Myofibrillar patterns are also similar to those described elsewhere (Ball \& Johnston, 1996; Lund \& Nielsen, 2001; Ogata et al., 1998; Swartz, Moss \& Greaser, 1997). By comparison of molecular weights, major structural proteins have been identified. Typical bands are indicated on the left side of Figure 1B. Much more proteolytic degradation by cathepsins were observed on myofibrillar proteins than on sarcoplasmic proteins.

Myosin heavy chain (MHC, $\sim 200 \mathrm{kDa}$ ) seemed to be very sensitive to all the three cathepsins and was degraded into two major fragments of about 150 and $140 \mathrm{kDa}$ (Figure 3). At the end of the incubation (21 hours), MHC had been completely degraded by cathepsin B. Noteworthy, cathepsin L had completely digested myofibrillar proteins in 21 hours since only MHC fragments were visible apart from a smear all over the rest of the lane.

Actin (42 kDa) intensity evolution was not significantly different from the control except with cathepsin L since actin had completely disappeared at the end of the incubation (Figure 3).

In the area of tropomyosin ( $34 \mathrm{kDa})$, another slightly higher molecular weight band of 37 $\mathrm{kDa}$ appeared and the $32 \mathrm{kDa}$ component was lost when incubation was performed with cathepsin B and L. This latter protein is assumed to be troponin T. Two fragments of $30 \mathrm{kDa}$ and $27 \mathrm{kDa}$ appeared when using cathepsin $\mathrm{B}$, only the one of $27 \mathrm{kDa}$ with cathepsin $\mathrm{D}$ and the one of $30 \mathrm{kDa}$ with cathepsin L (Figure 3).

Three other lower molecular weight bands (22, 20.1 and $18 \mathrm{kDa}$ ) were degraded by cathepsin $\mathrm{B}$ as indicated by the decrease of the band intensity. Three fragments appeared more intense soon after the beginning of incubation with cathepsin B (30 min) : $90 \mathrm{kDa}, 78$ and $73 \mathrm{kDa}$ (Figure 3).

The origin of fragments can not be determined precisely without using specific techniques such as partial sequencing or immunochemical tools. Western blots on myofibrillar proteins digestions were performed with antibodies to $\alpha$-actinin, tropomyosin and desmin when 
working on pellets and only $\alpha$-actinin on supernatants. $\alpha$-actinin (105 kDa) was slightly degraded by cathepsin B (Figure 4A) as indicated by the decrease of the immunochemical intensity of the band as well as the appearance of immunoreactive fragments of 97, 90, 80, 67 and $55 \mathrm{kDa}$ in 21 hours. Cathepsin $\mathrm{D}$ was able to degrade $\alpha$-actinin into fragments of $80 \mathrm{kDa}$ (major one), $72 \mathrm{kDa}, 67,56$ and $53 \mathrm{kDa}$ (Figure 4B). Cathepsin L was able to achieve the degradation of $\alpha$-actinin (Figure 4C) in 21 hours. Intermediate fragments of 84, 78, 72, 67, 64, 58 can be observed, with the $84 \mathrm{kDa}$ fragment being the major one. The pattern of degradation was then fairly different depending on the type of cathepsin. The final product of the $\alpha$-actinin degradation was the same for all the three cathepsins (37 kDa). Desmin (53 $\mathrm{kDa}$ ) band probed by the antibody became fainter upon proteolysis by each cathepsin but this decrease was also observed in the control (Figure 5). However, a more rapid disappearance seemed induced by cathepsins B and L. No degradation fragment was observed. Desmin is not degraded by cathepsin $\mathrm{D}$.

The tropomyosin ( $34 \mathrm{kDa}$ ) hybridised band became fainter upon the action of cathepsin $\mathrm{B}$ and cathepsin D but no hydrolytic fragments were visible with the antibody used (Figure 6A, 6B). In contrast, cathepsin L degraded tropomyosin from $34 \mathrm{kDa}$ to an about $32 \mathrm{kDa}$ protein which was hybridized as well by the antibody (Figure 6C).

The supernatants of the digestion of the myofibrils were constituted mostly by a fraction of myofibrillar proteins. They also can be considered to include proteins that are dissociated from complexes bound to the particulate fraction of the muscle cells.

We can observe, like for pellets, the degradation of MHC, actin, $34 \mathrm{kDa}$ tropomyosin component. A slight amount of $\alpha$-actinin was present in the early stages of incubation in the supernatant (data not shown). The amount of $\alpha$-actinin did not increase in the supernatants produced by cathepsin B but it was rising with cathepsins L and D (Figure 4). $\alpha$-actinin 105 $\mathrm{kDa}$ subunit from the supernatant was progressively lost with cathepsins $\mathrm{D}$ and $\mathrm{L}$ and some degradation fragments appeared at the end of the incubation $(69 \mathrm{kDa}$ for $\mathrm{D}$ and 98 and $68 \mathrm{kDa}$ for $\mathrm{L}$ ). Cathepsin B neither released nor degraded $\alpha$-actinin present in the supernatant.

It is worth noting that when myofibrils were digested by cathepsin B and cathepsin $\mathrm{D}$, the intensity of the $34 \mathrm{kDa}$ band corresponding to tropomyosin was increasing in the supernatant (data not shown) as it was confirmed by immunoblotting (Figure 6B). Thus, tropomyosin was not degraded by either cathepsin B or cathepsin D but was actually released from myofibrils in the soluble fraction. In contrast, the degradation of tropomyosin by cathepsin $\mathrm{L}$ in a $32 \mathrm{kDa}$ fragment was visible on immunoblots (Figure 6B). A third fragment (28 kDa) was produced during the degradation of tropomyosin by cathepsin L.

No release of desmin in the soluble fraction of the digests was observed (data not shown).

\section{Discussion}

The breakdown of fish muscle proteins is probably caused by several categories of proteases. Much of the focus on proteases and their role in postmortem processus has been directed toward calpains, cathepsins B, L and D (Hopkins \& Thompson, 2002). Some studies dealt with cathepsin $\mathrm{H}$ as well. Cathepsin $\mathrm{L}$ has been shown to play an important role in proteolysis in migrating chum salmon (Yamashita \& Konagaya, 1990a), in mackerel (Aoki \& Ueno, 1997) and carp muscle (Ogata et al., 1998). It has also been involved in the degradation of myofibrillar and sarcoplasmic proteins in salmon (Lund \& Nielsen, 2001). Jiang, Wang and Chen (1992) also showed the ability of cathepsin D to degrade tilapia myofibrils.

A number of in vitro studies have clearly demonstrated the susceptibility to proteolysis of numerous myofibrillar proteins by calpains and lysosomal proteinases. Our results revealed 
that MHC, $\alpha$-actinin, desmin, actin, troponin $\mathrm{T}$, tropomyosin and other unidentified protein bands can be degraded by cathepsins $\mathrm{B}$, D or L and are in accordance with those reported by several investigators. Aoki and Ueno (1997) found that cathepsin L in mackerel degraded myosin, troponin $\mathrm{T}$, troponin I and tropomyosin in contrast with cathepsin $\mathrm{B}$ which was unable to hydrolyse any of the myofibrillar proteins from mackerel white muscle. The effect of cathepsin L on myofibrillar proteins is similar to that reported by Aranishi, Ogata, Hara, Osatomi and Ishihara (1998) and Ogata et al. (1998) for carp cathepsin L. Yamashita and Konagaya (1991) also showed that cathepsin B produced less hydrolysis than cathepsin L on salmon muscle structural proteins and substrate specificity suggested that cathepsin $\mathrm{L}$ was the most probable enzyme participating in the muscle softening process. Jiang, Lee and Chen (1996) studied extensively the proteolysis of actomyosin by cathepsins B, L, L-like and X from mackerel and found that MHC was degraded by cathepsin B, cathepsin L and L-like while actin was only degraded by cathepsin L. Sarcoplasmic creatine kinase (41 kDa band) was already shown to be proteolysed by m-calpain (Purintrapiban, Wang \& Forsberg, 2001). Here, it was also degraded by cathepsin B and L.

Geesink, Morton, Kent and Bickerstaffe (2000) identified a $31 \mathrm{kDa}$ degradation product in the washed pellet of myofibrils during refrigerated storage of salmon muscle as well as during the in vitro digestion of myofibrils by calpain. It could be related to the $30 \mathrm{kDa}$ degradation fragment from troponin $\mathrm{T}$ found in tenderized mammalian muscles (Ho, Stromer \& Robson, 1994). In our study, assumed troponin $T$ was degraded by the cathepsins $B$ and $L$ with a concomitant appearance of a $30 \mathrm{kDa}$ band. Whether it is related to troponin $\mathrm{T}$ breakdown should be however assessed with immunological tools.

There is an extensive literature on postmortem changes in fish muscle including microscopy and biochemistry. Postmortem tenderization of fish muscle may be closely related to gradual degradation of the extracellular matrix (Ando, Toyohara, Shimizu \& Sakaguchi, 1991). In general, fish muscle shows little change in myofibrils postmortem especially in comparison to mammals. The changes which have been documented include the weakening and the disorganization of the $\mathrm{Z}$ line structure and detachment of sarcolemma (Papa et al., 1997), the degradation of titin, a giant protein anchored in Z line and nebulin (Astier et al., 1991; Busconi, Folco, Martone \& Sanchez, 1989), as well as the release of $\alpha$-actinin from the $\mathrm{Z}$ line and its degradation (Astier et al., 1991; Papa et al., 1996).

Titin degradation and $\alpha$-actinin release may serve as predictors of postmortem changes for bass, trout and carp (Papa et al., 1996). $\alpha$-actinin degradation yielded 80 and $40 \mathrm{kDa}$ fragments as major bands of autolysis in postmortem sea bass muscle. The release of this protein, occurring before the degradation of released molecules in muscles, was correlated with the calpain activity (Papa et al., 1996). In our study, the effect of the proteases on $\alpha$ actinin was complex. All the cathepsins degraded it in the pellet but only cathepsin D and L released it in the supernatant. No degradation of the supernatant form was observed with cathepsin B.

No degradation of MHC or troponin T occurred during postmortem storage of sea bass (Verrez-Bagnis et al., 2001). Lund and Nielsen (2001) observed a little change of myosin and no change of $\alpha$-actinin and actin during cold storage of salmon muscle. Martinez (1992) showed also that fish myosin degradation may take place during chilled storage in a species and tissue-dependent way. The three cathepsins degraded MHC in our experiment and troponin $\mathrm{T}$ was degraded by cathepsin $\mathrm{B}$ and $\mathrm{L}$.

We have found that desmin remained unchanged after refrigerated storage of cultured fish muscle (Verrez-Bagnis et al., 1999) whereas desmin is degraded during postmortem storage of bovine muscle (Olson, Parrish, Dayton \& Goll, 1977). But desmin is highly degraded in 
wild fish such as sardine (Verrez-Bagnis et al., 1999). Calpain was able to highly degrade sea bass desmin in vitro (Verrez-Bagnis et al., in press), cathepsin L seemed to degrade it also, although slightly. Since desmin was stable in postmortem sea bass muscle, it is unlikely that calpain is responsible for the initiation of the postmortem degradation as previously proposed.

\section{Conclusion}

In conclusion, MHC, desmin, actin, tropomyosin and the $32 \mathrm{kDa}$ band were shown to be stable in autolytic postmortem sea bass muscle but MHC was degraded in vitro by all the three proteases (cathepsin B, D, L) ; desmin was broken down by cathepsin B and L ; tropomyosin and actin were split by cathepsin $\mathrm{L}$, while the $32 \mathrm{kDa}$ troponin $\mathrm{T}$ was degraded by cathepsin B and L. Cathepsin L caused extensive degradation of the proteins which was not observed in the autolytic muscle. Taken together, our results suggest that cathepsin D could participate in the postmortem proteolysis by the release of $\alpha$-actinin and some other changes. The lysosomal localisation of the cathepsins could exclude their role in the initiation of the softening process. However, O'Halloran, Troy, Buckley and Reville (1997) reported that a high proportion of cathepsin B, D and L were present in the soluble fraction early postmortem.

To improve our analysis, we should take into account the evolution of the other huge proteins such as dystrophin, titin and nebulin. Due to their high molecular weights, they were not visible on our gels. Dystrophin degradation was shown to be a predictor of freeze thaw effect in bass and of the duration of chilled storage (Papa, Ventre, Lebart, Roustan \& Benyamin, 1996). The total degradation occurred within 48 hours (Papa et al., 1997).

This study led to the identification of in vitro substrates for cathepsins B, D and L but the elucidation of their exact role amongst the variety of lysosomal and non lysosomal proteases should be further clarified especially by the use in situ of specific inhibitors and by appropriate understanding of proteolytic activity regulation. It is clear that knowledge of the mechanisms underlying postmortem evolution of fish flesh is fragmented and often contradictory.

These kinds of studies would improve our understanding of the mechanisms related to the sarcomeric disintegration and the loss of the flesh texture. 


\section{Reference list}

Ando, M., Toyohara, H., Shimizu, Y., \& Sakaguchi, M. (1991). Post-mortem tenderisation of rainbow trout (Oncorhyncus mykiss) muscle caused by gradual disintegration of the extracellular matrix structure. Journal of the Science of Food and Agriculture, 55, 589597.

Aoki, T., \& Ueno, R. (1997). Involvement of cathepsins B and L in the post-mortem autolysis of mackerel muscle. Food Research International, 30(8), 585-591.

Aranishi, F., Ogata, H., Hara, K., Osatomi, K., \& Ishihara, T. (1998). Susceptibility of opioid peptides and myofibrillar proteins to carp cathepsin L. Journal of Agricultural and Food Chemistry, 46(2), 388-392.

Astier, C., Labbe, J.-P., Roustan, C., \& Benyamin, Y. (1991). Sarcomeric disorganization in post-mortem fish muscles. Comparative Biochemistry and Physiology, 100B(3), 459-465.

Ball, D., \& Johnston, I. A. (1996). Molecular mechanisms underlying the plasticity of muscle contractile properties with temperature acclimation in the marine fish Myoxocephalus scorpus. The Journal of Experimental Biology, 199, 1363-1373.

Bradford, M. M. (1976). A rapid and sensitive method for the quantification of microgram quantities of protein utilizing the principle of protein-dye binding. Analytical Biochemistry, 72, 248-254.

Busconi, L., Folco, E. J., Martone, C. B., \& Sanchez, J. J. (1989). Postmortem changes in cytoskeletal elements of fish muscle. Journal of Food Biochemistry, 13, 443-451.

Focant, B., Mélot, F., Collin, S., Chikou, A., Vandewalle, P., \& Huriaux, F. (1999). Muscle parvalbumin isoforms of Clarias gariepinus, Heterobranchus longifilis and Chrysichthys auratus : isolation, characterization and expression during development. Journal of Fish Biology, 54, 832-851.

Geesink, G., Morton, J., Kent, M., \& Bickerstaffe, R. (2000). Partial purification and characterization of Chinook salmon (Oncorhynchus tshawytscha) calpains and an evaluation of their role in postmortem proteolysis. Journal of Food Science, 65(8), 13181324.

Gerday, C. (1982). Soluble calcium-binding proteins from fish and invertebrate muscle. Molecular Physiology, 2, 63-87.

Girija, N., \& Rehbein, H. (1988). Comparison of parvalbumin patterns from different fish species by isoelectric focusing of muscle extracts. Comparative Biochemistry and Physiology, 91B(4), 723-728.

Goll, D. E., Thompson, V. F., Taylor, R. G., \& Christiansen, J. A. (1992). Role of the calpain system in muscle growth. Biochimie, 74, 225-237.

Ho, C. Y., Stromer, M. H., \& Robson, R. M. (1994). Identification of the 30kDa polypeptide in post mortem skeletal muscle as a degradation product of troponin-T. Biochimie, 76, 369375.

Ho, M., Chen, G., \& Jiang, S. (2000). Effects of mackerel cathepsins L and L-like, and calpain on the degradation of mackerel surimi. Fisheries Science, 66(3), 558-568.

Hopkins, D., \& Thompson, J. (2002). Factors contributing to proteolysis and disruption of myofibrillar proteins and the impact on tenderisation in beef and sheep meat. Australian Journal of Agricultural Research, (2), 149-166.

Jiang, S.-T., Lee, J.-J., \& Chen, H.-C. (1996). Proteolysis of actomyosin by cathepsins B, L, L-like, and X from mackerel (Scomber australasicus). Journal of Agricultural and Food Chemistry, 44, 769-773.

Jiang, S.-T., Wang, Y.-T., \& Chen, C.-S. (1992). Lysosomal enzyme effects on the postmortem changes in tilapia (Tilapia nilotica x T. aurea) muscle myofibrils. Journal of Food Science, 57(2), 277-279.

Kolodziejska, I., \& Sikorski, Z. E. (1995). Muscle cathepsins of marine fish and invertebrates. 
Polish Journal of Food and Nutrition Sciences, 4(45), 3-10.

Kubota, M., Kinoshita, M., Kubota, S., Yamashita, M., Toyohara, H., \& Sakaguchi, M. (2001). Possible implication of metalloproteinases in post-mortem tenderization of fish muscle. Fisheries Science, 67(5), 965-968.

Ladrat, C., Chaplet, M., Verrez-Bagnis, V., Noël, J., \& Fleurence, J. (2000). Neutral calciumactivated proteases from European sea bass (Dicentrarchus labrax L.) muscle : polymorphism and biochemistry studies. Comparative Biochemistry and Physiology, 125B, 83-95.

Laemmli, U. K. (1970). Cleavage of structural proteins during the assembly of the head of bacteriophage T4. Nature, 227, 680-685.

Lamare, M., Taylor, R. G., Farout, L., Briand, Y., \& Briand, M. (2002). Changes in proteasome activity during postmortem aging of bovine muscle. Meat Science, 61, 199204.

Lund, K., \& Nielsen, H. (2001). Proteolysis in salmon (Salmo salar) during cold storage; Effects of storage time and smoking process. Journal of Food Biochemistry, 25(5), 379395.

Martinez, I. (1992). Fish myosin degradation upon storage. In H. H. Huss, M. Jacobsen, \& J. Liston, Developments in Food Science, vol. 30 : Quality Assurance in the Fish Industry, (389-397). Amsterdam : Elsevier.

Matsuishi, M., \& Okitani, A. (1997). Proteasome from rabbit skeletal muscle : some properties and effects on muscle proteins. Meat Science, 45(4), 451-462.

Mykles, D. L., \& Haire, M. F. (1995). Branched-chain-amino-acid-prferring peptidase activity of the lobster multicatalytic proteinase (proteasome) and the degradation of myofibrillar proteins. Biochemical Journal, 306, 285-291.

Nakagawa, T., Watabe, S., \& Hashimoto, K. (1988a). Electrophoretic analysis of sarcoplasmic proteins from fish muscle on polyacrylamide gels. Nippon Suisan Gakkaishi, 54(6), 993-998.

Nakagawa, T., Watabe, S., \& Hashimoto, K. (1988b). Identification of three major components in fish sarcoplasmic proteins. Nippon Suisan Gakkaishi, 54(6), 999-1004.

O'Halloran, G. R., Troy, D. J., Buckley, D. J., \& Reville, W. J. (1997). The role of endogenous proteases in the tenderisation of fast glycolysing muscle. Meat Science, 47(3/4), 187-210.

Ogata, H., Aranishi, F., Hara, K., Osatomi, K., \& Ishihara, T. (1998). Proteolytic degradation of myofibrillar components by carp cathepsin L. Journal of the Science of Food and Agriculture, 76, 499-504.

Olson, D. G., Parrish, J. F. C., Dayton, W. R., \& Goll, D. E. (1977). Effect of postmortem storage and calcium activated factor on the myofibrillar proteins of bovine skeletal muscle. Journal of Food Science, 42, 117-124.

Papa, I., Alvarez, C., Verrez-Bagnis, V., Fleurence, J., \& Benyamin, Y. (1996). Post mortem release of fish white muscle $\alpha$-actinin as a marker of disorganisation. Journal of the Science of Food and Agriculture, 72(1), 63-70.

Papa, I., Taylor, R. G., Astier, C., Ventre, F., Lebart, M. C., Roustan, C., Ouali, A., \& Benyamin, Y. (1997). Dystrophin cleavage and sarcolemma detachment are early post mortem changes on bass (Dicentrarchus labrax) white muscle. Journal of Food Science, 62(5), 917-921.

Papa, I., Ventre, F., Lebart, M. C., Roustan, C., \& Benyamin, Y. (1996). Post mortem degradation of dystrophin from bass (Dicentrarchus labrax) white muscle. In Proceedings of the conference of IIR Commission C2. Refrigeration and Aquaculture, (pp153-157). Paris : International Institute of Refrigeration.

Purintrapiban, J., Wang, M., \& Forsberg, N. (2001). Identification of glycogen phosphorylase 
and creatine kinase as calpain substrates in skeletal muscle. International Journal of Biochemistry and Cell Biology, 33(5), 531-540.

Swartz, D. R., Moss, R. L., \& Greaser, M. L. (1997). Characteristics of tropinin C binding to the myofibrillar thin filament : extraction of troponin $C$ is not random along the length of the thin filament. Biophysical Journal, 73, 293-305.

Verrez-Bagnis, V., Ladrat, C., Morzel, M., Noël, J., \& Fleurence, J. (2001). Protein changes in postmortem sea bass (Dicentrarchus labrax) muscle monitored by one- and twodimensional gel electrophoresis. Electrophoresis, 22(8), 1539-1544.

Verrez-Bagnis V, Ladrat C, Noël J, \& Fleurence J. (2002). In vitro proteolysis of european sea bass (Dicentrarchus labrax) myofibrillar and sarcoplasmic proteins by an endogenous m-calpain. Journal of the Science of Food and Agriculture, 82, 1256-1262.

Verrez-Bagnis, V., Noël, J., Sautereau, C., \& Fleurence, J. (1999). Desmin degradation in postmortem fish muscle. Journal of Food Science, 64(2), 240-242.

Wang, K. (1982). Purification of titin and nebulin. Methods in Enzymology, 85, 264-274.

Yamashita, M., \& Konagaya, S. (1990a). Participation of cathepsin L into extensive softening of the muscle of chum salmon caught during spawning migration. Nippon Suisan Gakkaishi, 56(8), 1271-1277.

Yamashita, M., \& Konagaya, S. (1990b). Purification and characterization of cathepsin B from the white muscle of chum salmon, Oncorhychus keta. Comparative Biochemistry and Physiology, 96B(4), 733-737.

Yamashita, M., \& Konagaya, S. (1990c). Purification and characterization of cathepsin L from the white muscle of chum salmon, Oncorhychus keta. Comparative Biochemistry and Physiology, 96B(2), 247-252.

Yamashita, M., \& Konagaya, S. (1991). Hydrolytic action of salmon cathepsins B and L to muscle structural proteins in respect of muscle softening. Nippon Suisan Gakkaishi, 57(10), 1917-1922. 
Figure 1 : Annotated major sarcoplasmic and myofibrillar proteins. A : sarcoplasmic extract. B : myofibrillar extract. M: SDS-6H and SDS-7 markers : Myosin $205 \mathrm{kDa}$, ß-galactosidase $116 \mathrm{kDa}$, phosphorylase b $97.4 \mathrm{kDa}$, bovine albumin $66 \mathrm{kDa}$, egg albumin $45 \mathrm{kDa}$, glyceraldehyde-3-phosphate dehydrogenase $36 \mathrm{kDa}$, carbonic anhydrase $29 \mathrm{kDa}$, trypsinogen $24 \mathrm{kDa}$, trypsin inhibitor $20.1 \mathrm{kDa}$, $\alpha$ lactalbumin $14.2 \mathrm{kDa}$.
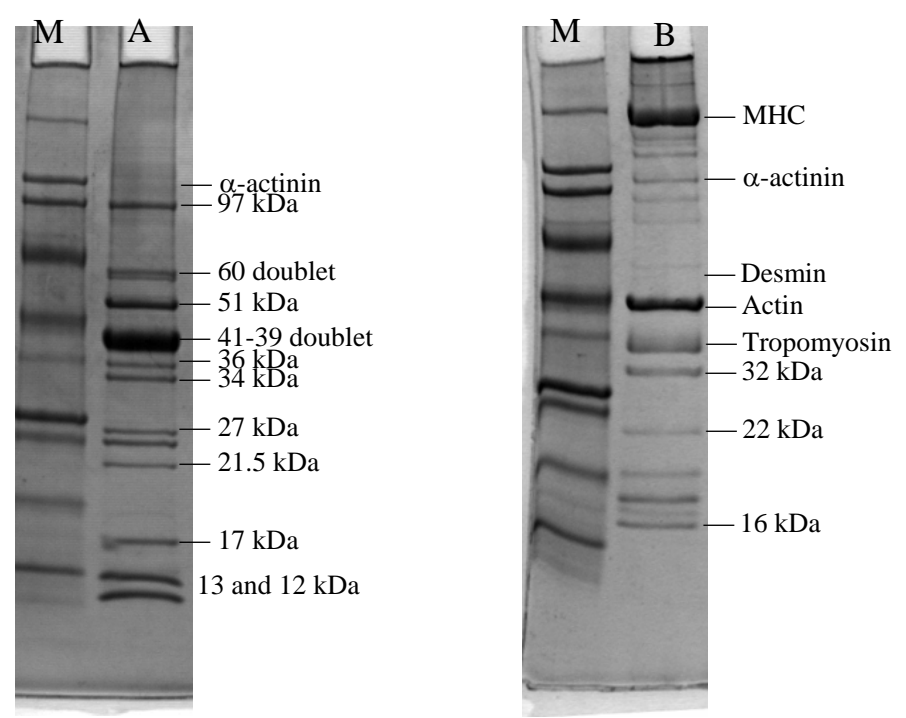
Figure 2 : Effect of cathepsins on sarcoplasmic proteins analysed by SDS-PAGE and Coomassie blue staining. A : cathepsin B ; B : cathepsin D, C : cathepsin L. Lanes 1 and 9 : SDS6H and SDS-7 markers (see legend to figure 1), lane $2: 0$ min of incubation, lane $3: 30$ min, lane $4: 1$ hour, lane $5: 2$ hours, lane $6: 4$ hours, lane $7: 6$ hours, lane $8: 22$ hours, lane 10 : sarcoplasmic extract.

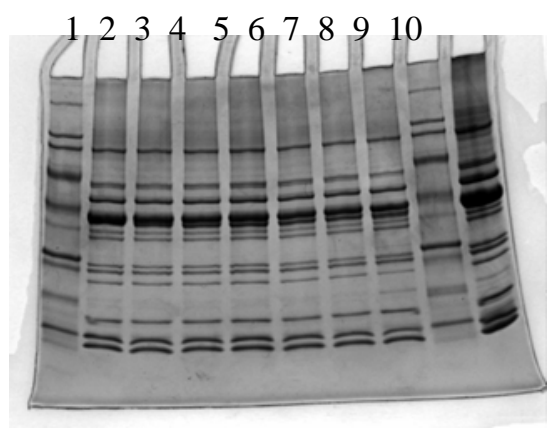

A

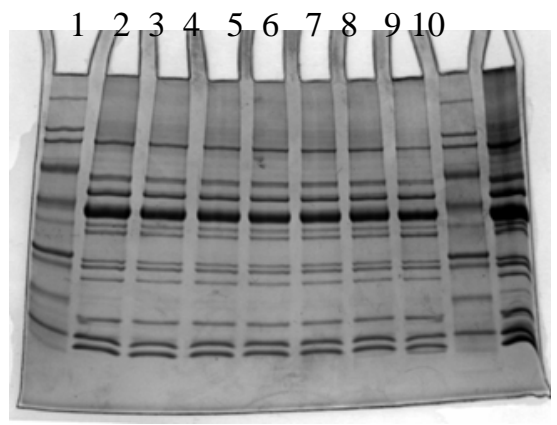

B

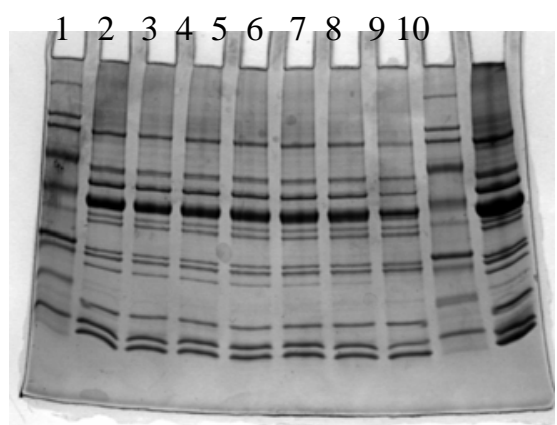

C 
Figure 3 : Effect of cathepsins on structural proteins analysed by SDS-PAGE and Coomassie blue staining. A : cathepsin B, B : cathepsin D, C : cathepsin L, D : control without cathepsin. Lanes 1 and $9:$ SDS6H and SDS-7 markers (see legend to figure 1), lane $2: 0$ min of incubation, lane $3: 30 \mathrm{~min}$, lane $4: 1$ hour, lane $5: 2$ hours, lane $6: 4$ hours, lane $7: 6$ hours, lane $8: 22$ hours, lane $10:$ initial myofibrils extract.

A

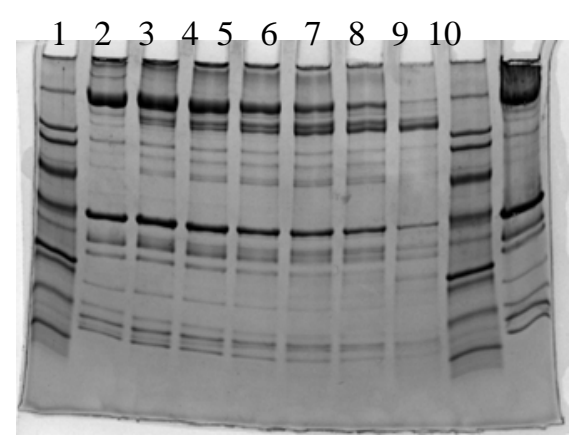

C

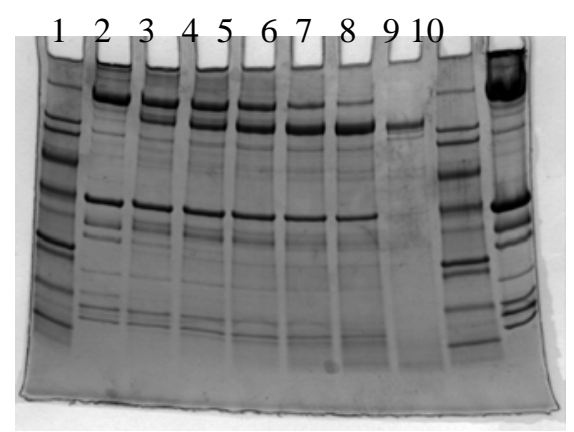

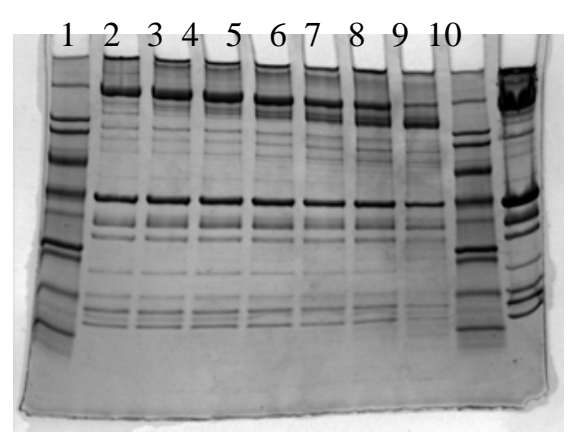

$\mathrm{D}$

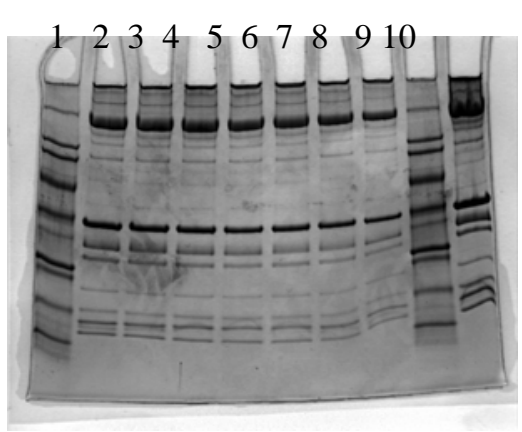


Figure 4 : Effect of cathepsins on $\alpha$-actinin detected by immunoblots. A : cathepsin B, B : cathepsin D, C : cathepsin L, D : control without cathepsin. Pellet : lane $1: 0$ min, lane $2: 30$ min, lane $3: 1$ hour, lane $4: 2$ hours, lane $5: 4$ hours, lane $6: 6$ hours, lane $7: 22$ hours, lane 8 : prestained markers, lane 9 : initial myofibrils. Supernatant : lane $1: 0 \mathrm{~min}$, lane $2: 30 \mathrm{~min}$, lane $3: 1$ hour, lane $4: 2$ hours, lane $5: 4$ hours, lane $6: 6$ hours, lane $7:$ prestained markers, lane $8: 22$ hours.

Pellet Supernatant

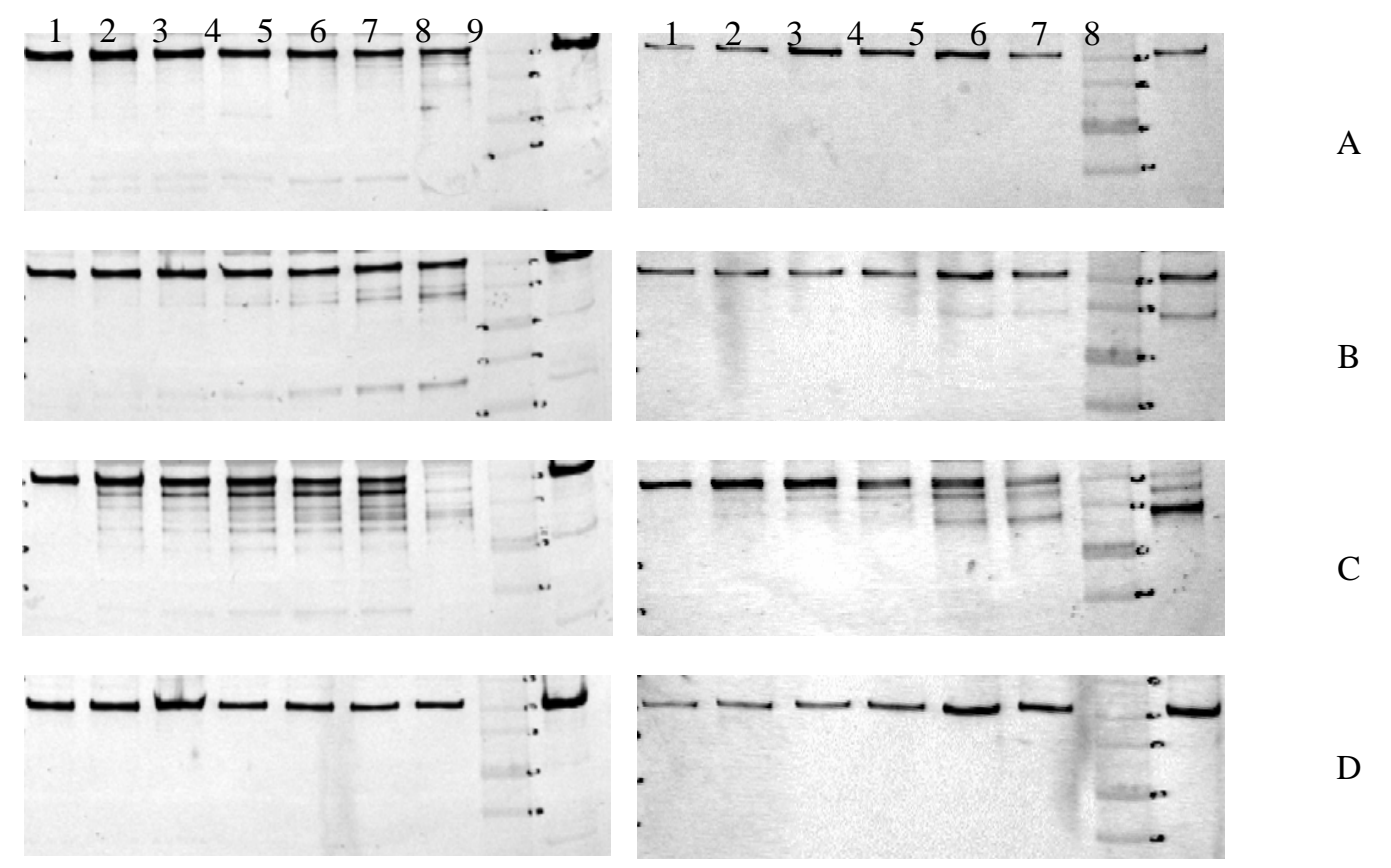


Figure 5 : Effect of cathepsins on desmin detected by immunoblots. A : cathepsin B, B : cathepsin D, C : cathepsin L, D : control without cathepsin. Lane $1: 0 \mathrm{~min}$, lane $2: 30 \mathrm{~min}$, lane $3: 1$ hour, lane $4: 2$ hours, lane $5: 4$ hours, lane $6: 6$ hours, lane $7: 22$ hours, lane 8 : prestained markers, lane 9 : initial myofibrils.

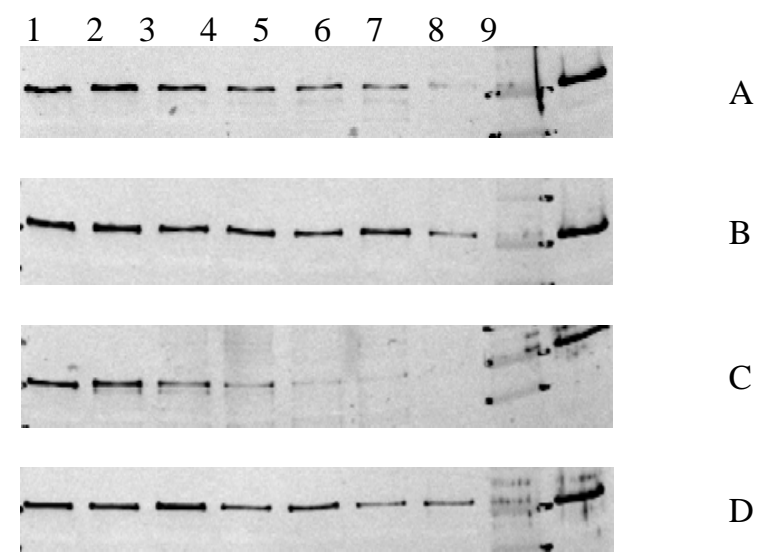


Figure 6 : Effect of cathepsins on tropomyosin detected by immunoblots. A : cathepsin B, B : cathepsin D, C : cathepsin L, D : control without cathepsin. Pellet : lane $1: 0$ min, lane $2: 30$ min, lane $3: 1$ hour, lane $4: 2$ hours, lane $5: 4$ hours, lane $6: 6$ hours, lane $7: 22$ hours, lane 8 : prestained markers, lane 9 : initial myofibrils. Supernatant : lane $1: 0 \mathrm{~min}$, lane $2: 30 \mathrm{~min}$, lane $3: 1$ hour, lane $4: 2$ hours, lane $5: 4$ hours, lane $6: 6$ hours, lane $7:$ prestained markers, lane $8: 22$ hours.

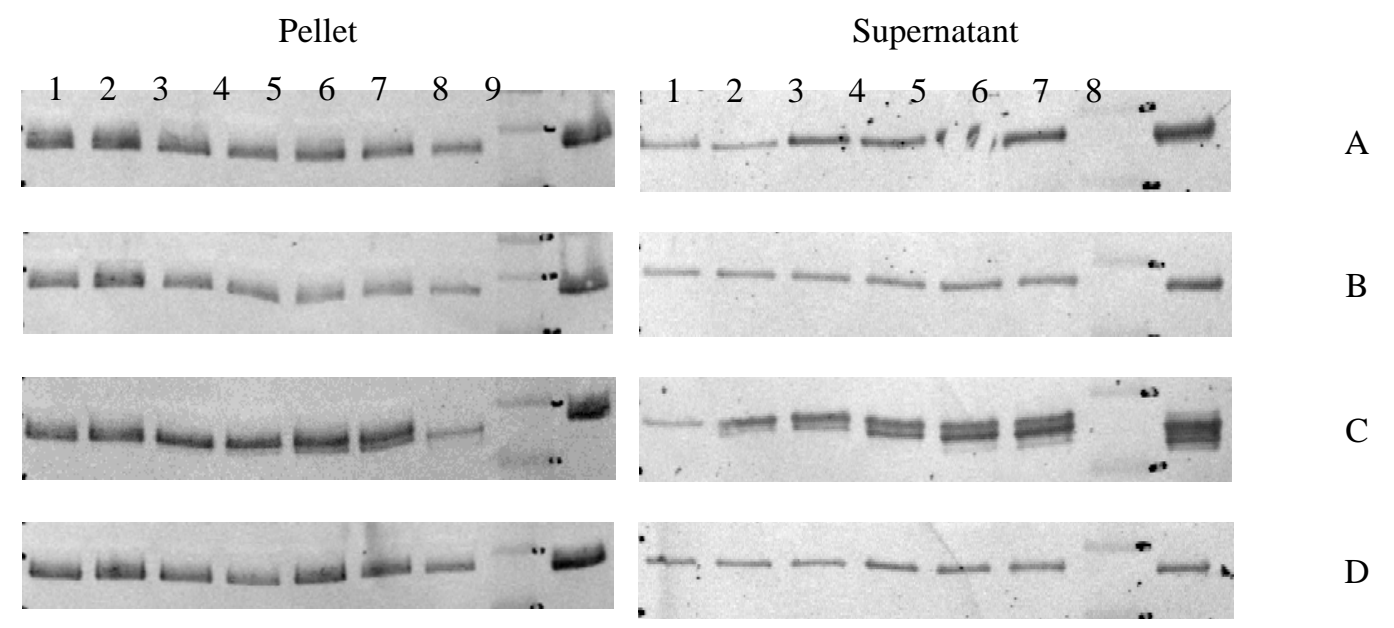

